\title{
Abnormal Bone Development
}

National Cancer Institute

\section{Source}

National Cancer Institute. Abnormal Bone Development. NCI Thesaurus. Code C78221.

A finding referring to deviation from or interruption of normal development of the bones. 